\title{
Control of Dye Aggregation and Electron Injection for Highly Efficient Porphyrin Sensitizers Adsorbed on Semiconductor Films with Varying Ratios of Coadsorbate
}

\author{
Hsueh-Pei Lu, ${ }^{\dagger}$ Chen-Yuan Tsai, ${ }^{\dagger}$ Wei-Nan Yen,${ }^{\dagger}$ Chou-Pou Hsieh,$\stackrel{ }{\dagger}$ Cheng-Wei Lee, ${ }^{\dagger,}$, \\ Chen-Yu Yeh,*,* and Eric Wei-Guang Diau*, \\ Department of Applied Chemistry and Institute of Molecular Science, National Chiao Tung University, \\ Hsinchu 300, Taiwan, and Department of Chemistry, National Chung Hsing University, Taichung 402, Taiwan
}

Received: August 22, 2009; Revised Manuscript Received: October 21, 2009

\begin{abstract}
We report the photovoltaic performances and kinetics of femtosecond fluorescence for three zinc-porphyrin sensitizers (YD0-YD2) coadsorbed with chenodeoxycholic acid (CDCA) at three molar ratios on nanocrystalline semiconductor $\left(\mathrm{TiO}_{2}\right.$ or $\left.\mathrm{Al}_{2} \mathrm{O}_{3}\right)$ films. The addition of CDCA improved the efficiencies of YD0 and YD1 so that their maximum performance occurred at a dye/CDCA ratio of 1:2, but the presence of CDCA had a negative effect for YD2. Porphyrin aggregation on $\mathrm{TiO}_{2}$ surfaces not only accelerates the rate of intermolecular energy transfer but also increases the rate of interfacial electron injection, so that the electron injection yields $\left(\Phi_{\text {inj }}\right)$ are balanced by these two important factors. As a result, $\Phi_{\text {inj }}$ increased slightly with increasing amount of CDCA for both YD0 and YD1, but decreased for YD2; for this reason, the presence of CDCA failed to improve the photovoltaic performance for YD2, unlike for YD0 and YD1. The cell performances were optimized on $\mathrm{TiO}_{2}$ films of $\sim 10-\mu \mathrm{m}$ thickness with a scattering layer of $\sim 4-\mu \mathrm{m}$ thickness: the efficiencies of power conversion of YD1 and YD2 are slightly smaller than, but near, that of N719, being $6.5 \%$ and $6.8 \%$, respectively, compared to $7.3 \%$. Without a scattering layer on the films, the performance of N719 was degraded significantly (6.3\%), whereas the efficiencies of YD1 and YD2 decreased only slightly $(6.4 \%$ and $6.6 \%)$, making this series of green sensitizers promising candidates for future light-penetrable photovoltaic applications.
\end{abstract}

\section{Introduction}

With advantages of low cost, low weight, coloring, and easy processing, dye-sensitized solar cells (DSSCs) are prospective alternatives for future devices for the conversion of solar energy, complementary to silicon-based solar cells. ${ }^{1}$ DSSC devices with $\mathrm{Ru}$ complexes as photosensitizers have attained the greatest efficiency of power conversion, $\eta \approx 11 \%,{ }^{2}$ but a limited availability of $\mathrm{Ru}$ dyes and associated environmental concerns have stimulated much effort to find alternative, cheaper, and safer organic-based dyes. ${ }^{3}$ Among those non-Ru-based dyes, porphyrin chromophores are promising candidates because they capture solar energy efficiently. Numerous reports of porphyrinbased DSSC have appeared. ${ }^{3 \mathrm{~d}, 4}$ For example, a DSSC device with porphyrin sensitizers and a $\pi$-conjugated anchoring group functionalized at the $\beta$-position was reported to attain an efficiency of power conversion of $\eta=7.1 \%,{ }^{4 b}$ and a device made of a $\beta, \beta^{\prime}$-edge-fused zinc porphyrin with quinoxaline moiety exhibited a comparable cell performance, $\eta=6.3 \%{ }^{3 \mathrm{~d}}$ We reported a novel zinc porphyrin dye (YD1) ${ }^{5}$ that has in its molecular structure an electron-donating diarylamino group attached at the meso position of the porphyrin ring opposite the meso-substituted phenylethynyl carboxyl anchoring group; a device made from this YD1 dye was found to have a cell performance similar to that of a Ru-based DSSC, making the push-pull porphyrin the most efficient green dye for DSSC applications. ${ }^{5}$

\footnotetext{
* Corresponding authors. E-mail: cyyeh@ dragon.nchu.edu.tw (C.-Y.Y.), diau@mail.nctu.edu.tw (E.W.-G.D.).

${ }^{\dagger}$ National Chiao Tung University.

${ }^{\ddagger}$ National Chung Hsing University.
}

CHART 1: Molecular Structures of Three Zinc Porphyrin Sensitizers

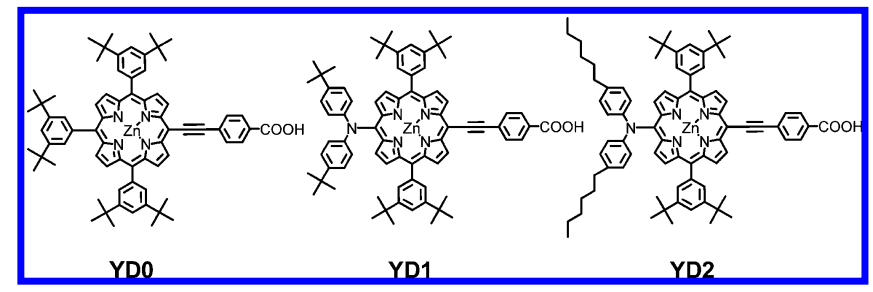

The effect of aggregation on the $\mathrm{TiO}_{2}$ surface is an important issue in further improving the cell performance of porphyrin-based DSSCs. ${ }^{4-6}$ Aggregates do not contribute to photocurrent generation in devices made of tetrachelate porphyrin chromophores, ${ }^{4 c}$ and some push-pull porphyrins likewise suffer from dye aggregation. ${ }^{5}$ To suppress dye aggregation on the $\mathrm{TiO}_{2}$ surface, a remedy is to add a coadsorbate into the dye solution when fabricating sensitized $\mathrm{TiO}_{2}$ films into devices. The most popular coadsorbate is chenodeoxycholic acid (CDCA),${ }^{4 a, 5}$ but other coadsorbates with either long alkyl chains (e.g., hexadecylmalonic acid or HDMA $)^{7}$ or bulky groups [e.g., dineohexyl bis(3,3-dimethylbutyl)phosphinic acid, or DINHOP] ${ }^{8}$ have also been reported. We report here results of our systematic characterizations of three zinc porphyrin sensitizers, YD0-YD2 (Chart 1), coadsorbed with CDCA at three ratios on $\mathrm{TiO}_{2}$ films with thicknesses of 5-10 $\mu \mathrm{m}$ with and without an added scattering layer with a thickness of $\sim 4 \mu \mathrm{m}$. Without a diarylamino group, YD0 served as a reference for comparison with YD1 and YD2. The diarylamino motif has been commonly applied in the preparation of push-pull organic dyes for HOMO-LUMO tuning. ${ }^{9}$ YD2 was modified from YD1 in that 


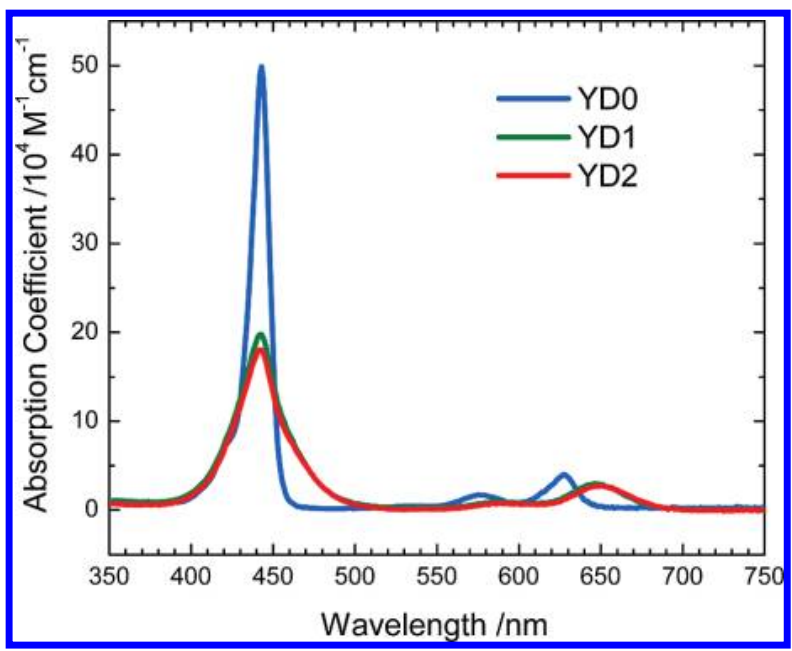

Figure 1. Calibrated absorption spectra of YD0-YD2 in ethanol.

the two tert-butyl groups in the diarylamino substituent were replaced with two long alkyl chains to improve its thermal and photochemical stability in a device. ${ }^{10}$ This design mimics the strategy applied in an amphiphilic ruthenium polypyridyl sensitizer (Z907) that has shown excellent stability toward waterinduced desorption under both thermal stress and light-soaking conditions. ${ }^{11}$ The cell performances of YD0 and YD1 improved upon addition of CDCA at a dye/CDCA ratio of 1:2, whereas that of YD2 decreased in the presence of CDCA. With femtosecond fluorescence up-conversion applied to both porphyrin-sensitized $\mathrm{TiO}_{2}$ and $\mathrm{Al}_{2} \mathrm{O}_{3}$ films, we estimated the electron-injection yield $\left(\Phi_{\text {inj }}\right)$ for YD0-YD2 and rationalized the discrepancy between YD1 and YD2.

\section{Results and Discussion}

The syntheses of YD0 and YD1 are described elsewhere, ${ }^{5}$ and that of YD2 is available in the Supporting Information. Figure 1 shows absorption spectra of YD0-YD2 in ethanol solution. Because of the electronic coupling between the aromatic substituent and the porphyrin ring, the Soret bands of YD1 and YD2 are broader and the Q bands of YD1 and YD2 are significantly shifted toward longer wavelengths compared to YD0. The absorption spectra of YD1 and YD2 are similar, apart from a slightly red-shifted shoulder of the Q band of YD2. The spectral features of YD1 and YD2 with broad Soret band and red-shifted $\mathrm{Q}$ bands serve to increase the harvesting of solar energy in a DSSC device, as explained in the following section.

2.1. Photovoltaic Properties of YD0-YD2 Coadsorbed with CDCA at Varying Ratios. These three porphyrins were sensitized on $\mathrm{TiO}_{2}$ films with thicknesses of $L \approx 5 \mu \mathrm{m}$ and fabricated into DSSC devices to characterize their photovoltaic performance (Supporting Information). The photovoltaic measurements were performed with five identical working electrodes for each porphyrin (YD0-YD2) coadsorbed with CDCA at varying molar ratios under the same experimental conditions. The raw data for each current-voltage $(J-V)$ measurement are summarized in Tables S1-S4 (Supporting Information) for YD0-YD2 and N719, respectively; the corresponding averaged photovoltaic parameters are summarized in Table 1. Figure $2 \mathrm{a}-\mathrm{c}$ shows typical $J-V$ curves (working electrode a in Tables S1-S3 in the Supporting Information) of the porphyrin-based DSSC devices for YD0-YD2, respectively, with CDCA at varying molar ratios as indicated. Our results demonstrate two important points: the efficiencies of power conversion of YD1 and YD2 are significantly greater than those of YD0, reflecting the values of the short-circuit photocurrent density $\left(J_{\mathrm{SC}}\right)$, and the addition of CDCA improved both the open-circuit voltage $\left(V_{\mathrm{OC}}\right)$ and the filling factor (FF) for all sensitizers. $V_{\mathrm{OC}}$ and FF in the presence of CDCA increase through suppression of dye aggregation ${ }^{4 a, 5}$ to increase the injected electrons and modification of the $\mathrm{TiO}_{2}$ electrode surface to increase electron interception. ${ }^{3 \mathrm{~b}} J_{\mathrm{SC}}$ has a maximum value at a dye/CDCA ratio of 1:2 for YD0 and YD1, in contrast with a maximum of $J_{\mathrm{SC}}$ in the absence of CDCA for YD2. The loading of dye (Table 1) systematically decreased with decreasing ratio of dye to CDCA for all three sensitizers; this trend is consistent with the variation of $J_{\mathrm{SC}}$ in YD2. The presence of CDCA thus failed to improve the cell performance of YD2, unlike for YD0, YD1, and other porphyrin sensitizers. For $\mathrm{TiO}_{2}$ films with a thickness of $\sim 5 \mu \mathrm{m}$, the performance of the YD2 device in the absence of CDCA attained an efficiency of $\eta=5.7 \%$, slightly greater than that of $\mathbf{N 7 1 9}(\eta=5.5 \%)$ through the significantly greater $J_{\mathrm{SC}}$ of the former (11.0 vs 9.3 $\mathrm{mA} \mathrm{cm}{ }^{-2}$ ).

Figure $3 a-c$ shows spectra for the incident photon to current conversion efficiency (IPCE) of the same DSSC devices whose $J-V$ characteristics appear in Figure $2 \mathrm{a}-\mathrm{c}$; the dashed curves represent the corresponding light-harvesting efficiencies (LHE) obtained from absorption spectra of the sensitized $\mathrm{TiO}_{2}$ films. Integrating the IPCE over the AM $1.5 \mathrm{G}$ solar spectrum yields a calculated $J_{\mathrm{SC}}$ value similar to the collected value for all devices under investigation (Supporting Information Figure S1), thus validating the $J-V$ results shown in Figure 2. The IPCE spectra of YD0-YD2 mimic the corresponding LHE spectra in the range of $400-700 \mathrm{~nm}$. We deduced two features from our IPCE results to account for the cell performances of YD1 and YD2 being superior to that of YD0. First, the IPCE spectra of YD1 and YD2 exhibit Soret and Q bands that are broadened and red-shifted relative to those of YDO, improving the light harvesting of the former. Second, the gaps between the LHE and IPCE spectra of YD1 and YD2 (20\%) are smaller than that of YD0 $(\sim 30 \%)$, thereby increasing the capabilities of electron injection and charge collection for the former. As a result, the $J_{\text {SC }}$ values of YD1 and YD2 are significantly greater than that of YD0. The presence of CDCA decreases the LHE for all porphyrins, but the IPCE spectra of YD0 and YD1 differ from that of YD2; the IPCE values are greatest for YD0 and YD1 for a dye/CDCA ratio of 1:2, whereas the IPCE spectrum of YD2 varies little with dye/CDCA ratio. The IPCE results shown in Figure 3 are thus consistent with the $J-V$ results shown in Figure 2.

2.2. Enduring Charge-Separation States of YD1 and YD2 on $\mathbf{T i O}_{2}$ Films. The absorption (or LHE) spectra of the YD1/ $\mathrm{TiO}_{2}$ and $\mathbf{Y D 2} / \mathrm{TiO}_{2}$ films feature an additional band at about $\sim 800 \mathrm{~nm}$, which YD0 lacks. As the IPCE spectra of YD1 and YD2 show no signal near $\sim 800 \mathrm{~nm}$, this 800 -nm absorption band makes no contribution to photocurrent generation. In our work on the spectroelectrochemistry of YD1, two characteristic bands at $\sim 800$ and $\sim 1350 \mathrm{~nm}$ were unambiguously observed for the oxidized species of YD1. ${ }^{5}$ Such a spectral feature for the $\mathrm{YD1} / \mathrm{TiO}_{2}$ and $\mathrm{YD} 2 / \mathrm{TiO}_{2}$ films thus indicates the formation of the dye cationic species. To confirm this deduction, we performed additional experiments in three steps and observed the following results (Figure 4): (i) the 800- and 1350-nm bands were absent when we initially prepared a YD1/TiO ${ }_{2}$ film under dark conditions, (ii) the two characteristic absorption bands appeared after the film was exposed to a lamp $\left(100 \mathrm{~mW} \mathrm{~cm}^{-2}\right)$ for $1 \mathrm{~min}$, and (iii) this spectral feature persisted until the film was further rinsed with a ferrocene/tert-butanol solution that eliminated the cationic spectral feature because $\mathbf{Y D 1}^{+}$became 
TABLE 1: Photovoltaic Parameters of DSSCs with $\mathrm{TiO}_{2}$ Films $(L \approx 5 \mu \mathrm{m})$ Sensitized with YD0-YD2 and N719 Coadsorbed with Varying CDCA Ratios under Simulated AM-1.5 Illumination (Power $=100 \mathrm{~mW} \mathrm{~cm} \mathrm{~cm}^{-2}$ ) and an Active Area of $0.16 \mathrm{~cm}^{2} a$

\begin{tabular}{|c|c|c|c|c|c|c|}
\hline dye & dye/CDCA ratio & dye loading $\left(\mathrm{nmol} \mathrm{cm}^{-2}\right)$ & $J_{\mathrm{SC}}\left(\mathrm{mA} \mathrm{cm}^{-2}\right)$ & $V_{\mathrm{OC}}(\mathrm{V})$ & FF & $\eta(\%)$ \\
\hline \multirow[t]{3}{*}{ YD0 } & $1: 0$ & 50 & $6.46 \pm 0.15$ & $0.693 \pm 0.004$ & $0.727 \pm 0.015$ & $3.25 \pm 0.09$ \\
\hline & $1: 2$ & 40 & $7.43 \pm 0.52$ & $0.707 \pm 0.009$ & $0.722 \pm 0.058$ & $3.79 \pm 0.06$ \\
\hline & $1: 10$ & 35 & $6.30 \pm 0.14$ & $0.699 \pm 0.009$ & $0.735 \pm 0.010$ & $3.24 \pm 0.03$ \\
\hline \multirow{2}{*}{ YD1 } & $1: 2$ & 50 & $10.12 \pm 0.56$ & $0.720 \pm 0.005$ & $0.726 \pm 0.011$ & $5.29 \pm 0.23$ \\
\hline & $1: 10$ & 46 & $9.05 \pm 0.54$ & $0.720 \pm 0.007$ & $0.717 \pm 0.031$ & $4.67 \pm 0.09$ \\
\hline YD2 & $1: 0$ & 72 & $11.00 \pm 0.44$ & $0.729 \pm 0.004$ & $0.710 \pm 0.010$ & $5.69 \pm 0.15$ \\
\hline N719 & $1: 1$ & 96 & $9.31 \pm 0.20$ & $0.792 \pm 0.010$ & $0.744 \pm 0.013$ & $5.48 \pm 0.10$ \\
\hline
\end{tabular}

${ }^{a}$ Photovoltaic parameters are average values obtained from analysis of $J-V$ curves of five identical working electrodes for each device fabricated and characterized under the same experimental conditions. The raw data of each $J-V$ measurement are summarized in Tables $\mathrm{S} 1-\mathrm{S} 4$ (Supporting Information); the uncertainties represent two standard deviations of the measurements.

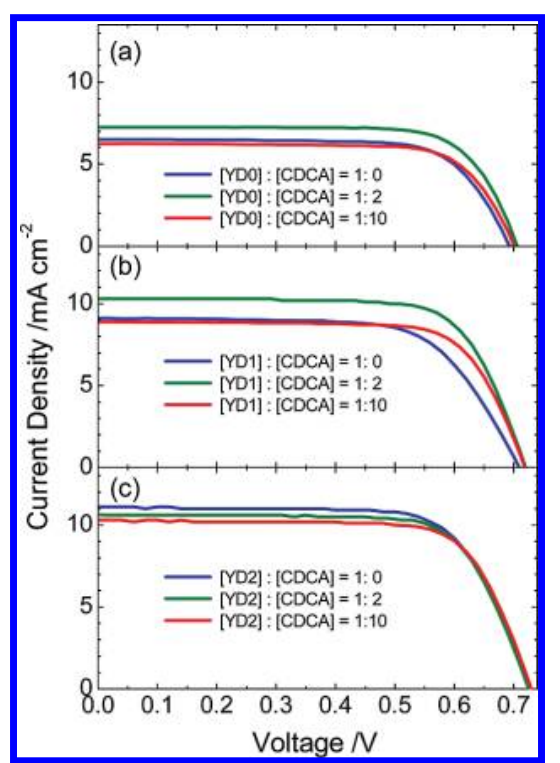

Figure 2. Current-voltage characteristics of DSSC devices (working electrode a in the Supporting Information) with sensitizers of (a) YD0, (b) YD1, and (c)YD2 coadsorbed with CDCA in three ratios on a $\mathrm{TiO}_{2}$ film with a thickness of $\sim 5 \mu \mathrm{m}$ under illumination with simulated AM1.5G full sunlight $\left(100 \mathrm{~mW} \mathrm{~cm}{ }^{-2}\right)$ and an active area of $0.16 \mathrm{~cm}^{2}$.

reduced to YD1 by ferrocene; the same is true for YD2. We thereby confirmed that the appearance of the absorption band at $800 \mathrm{~nm}$ is due to the formation of an enduring cationic state of YD1 or YD2 on a $\mathrm{TiO}_{2}$ film after photoinduced charge separation; this result implies the excellent character of charge separation in the $\mathbf{Y D 1} / \mathrm{TiO}_{2}$ and $\mathbf{Y D 2} / \mathrm{TiO}_{2}$ films with protracted charge recombination.

The observed retardation of charge recombination might reflect an optimal spatial separation between the amino moiety and the $\mathrm{TiO}_{2}$ surface reported for a Ru-dye system. ${ }^{12}$ For the porphyrin system, the period for charge recombination of a triarylamine-substituted porphyrin/ $/ \mathrm{TiO}_{2}$ film is 20 times that of a free-base porphyrin counterpart ( $80 \mathrm{vs} 4 \mathrm{~ms}$ ). ${ }^{13}$ The smaller $V_{\mathrm{OC}}$ of porphyrin-sensitized solar cells reflects a decreased electron lifetime related to a rapid recombination of electrons with either dye cations or $\mathrm{I}_{3}{ }^{-}$ions. ${ }^{14}$ In our work, an enduring charge separation in porphyrin-sensitized $\mathrm{TiO}_{2}$ films implies that the interception of conduction-band electrons is controlled solely by recombination of electrons with $\mathrm{I}_{3}{ }^{-}$. That the observed $V_{\mathrm{OC}}$ value in a YD1- or YD2-based DSSC is larger than those in YD0- and other porphyrin-based devices ${ }^{4,14}$ is thus inferred to be due to the diminished recombination between $\mathrm{I}_{3}{ }^{-}$and

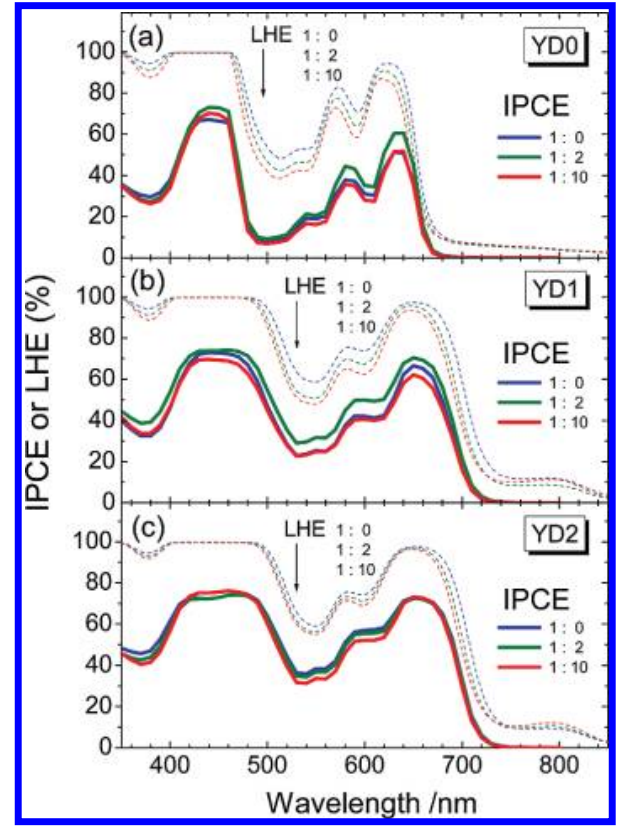

Figure 3. Corresponding action spectra for the efficiency of conversion of incident photons into current (IPCE) of the same DSSC devices as used for Figure 2. Dashed curves show the corresponding spectra of light-harvesting efficiency (LHE).

conduction-band electrons, because $\mathrm{I}_{3}{ }^{-}$might attach to the positively charged diarylamino moiety far from the $\mathrm{TiO}_{2}$ surface.

2.3. Effect of CDCA on APCE Spectra. $J_{\mathrm{SC}}$ plays an important role in the efficiency of DSSC devices; the cell performance with varying CDCA ratio can thus be understood from the IPCE spectra in Figure 3. At each wavelength $\lambda$, the IPCE depends on the LHE, the quantum yield of electron injection $\left(\Phi_{\text {inj }}\right)$, and the efficiency of charge collection at the counter electrode $\left(\eta_{\mathrm{c}}\right)$ according to the expression ${ }^{1 \mathrm{~b}, 15}$

$$
\operatorname{IPCE}(\lambda)=\operatorname{LHE}(\lambda) \Phi_{\mathrm{inj}} \eta_{\mathrm{c}}
$$

Because $\operatorname{LHE}(\lambda)$ reflects the native absorption ability of a dye to capture the solar energy at wavelength $\lambda$, it is helpful to understand the electron-transport kinetics by expressing the absorbed photon to current conversion efficiency (APCE) according to ${ }^{15}$

$$
\operatorname{APCE}=\operatorname{IPCE}(\lambda) / \operatorname{LHE}(\lambda)=\Phi_{\mathrm{inj}} \eta_{\mathrm{c}}
$$




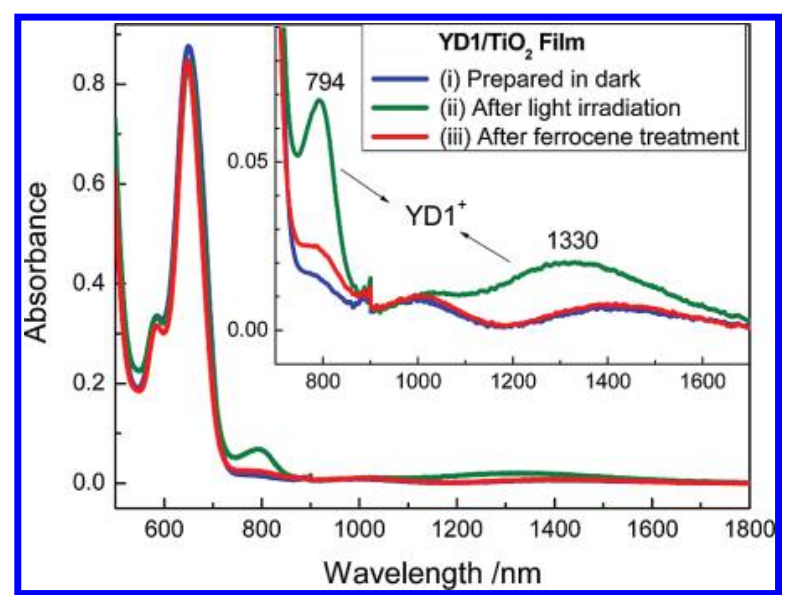

Figure 4. Absorption spectra of a YD1/TiO ${ }_{2}$ film $(L \approx 5 \mu \mathrm{m})$ under consecutive processing. The film was (i) prepared initially in a dark environment, (ii) then irradiated with simulated sunlight $\left(100 \mathrm{~mW} \mathrm{~cm}{ }^{-2}\right)$ for $1 \mathrm{~min}$, and (iii) finally rinsed with drops of a ferrocene/tert-butanol solution. The inset shows the corresponding enlarged spectra.

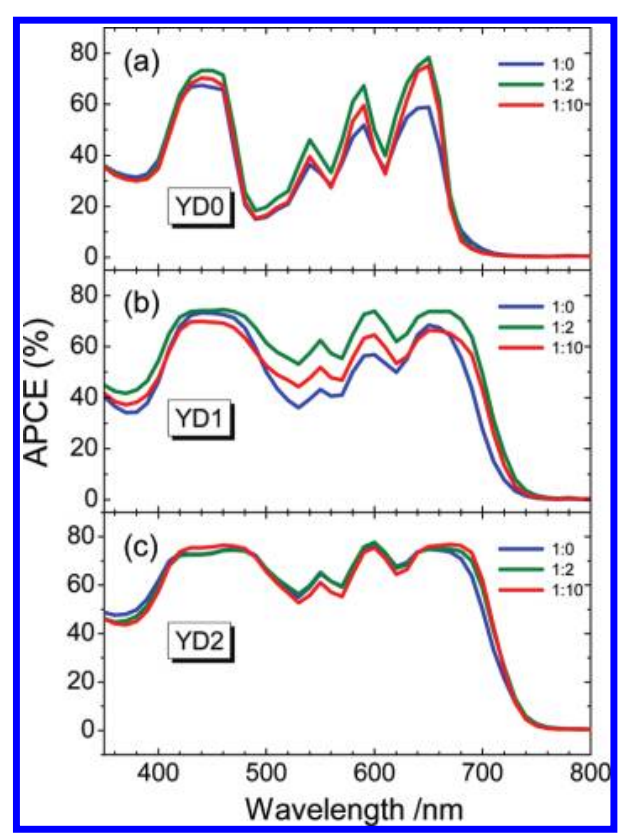

Figure 5. Spectra for the efficiency of conversion of absorbed photons to current (APCE) transformed from the corresponding IPCE and LHE spectra according to eq 2 .

Figure 5a-c displays APCE spectra for YD0-YD2, respectively. The APCE values depend strongly on $\lambda$ for YD0, but are less sensitive to $\lambda$ in the visible region for YD1 and YD2; the effect of CDCA on APCE is more pronounced for YD1, whereas the presence of CDCA has almost no influence on APCE for YD2. As APCE involves two parameters, namely, $\Phi_{\text {inj }}$ and $\eta_{\mathrm{c}}$, the factor affecting the photovoltaic performances of these devices is understandable if one parameter can be well characterized. To estimate $\Phi_{\text {inj }}$ for the corresponding devices, we therefore measured femtosecond fluorescence up-conversion for $\mathrm{TiO}_{2}$ films with thicknesses of $5 \mu \mathrm{m}$ sensitized with YD0-YD2 with CDCA added at various ratios.

2.4. Femtosecond Fluorescence Decays of YD0-YD2 on $\mathrm{TiO}_{2}$ and $\mathrm{Al}_{2} \mathrm{O}_{3}$ Films. To investigate the dynamics of interfacial electron injection in porphyrin-sensitized $\mathrm{TiO}_{2}$ films, we measured femtosecond fluorescence decays with porphyrinsensitized $\mathrm{Al}_{2} \mathrm{O}_{3}$ films serving as references. The nanocrystalline $\mathrm{TiO}_{2}$ films were prepared by the same method as was used for photovoltaic measurements; the preparation of nanocrystalline
$\mathrm{Al}_{2} \mathrm{O}_{3}$ films of the same thickness $(L \approx 5 \mu \mathrm{m})$ is described in Supporting Information. To ensure that the amounts of dye loading on the two films are similar, we controlled the absorbances of the porphyrins on $\mathrm{TiO}_{2}$ and $\mathrm{Al}_{2} \mathrm{O}_{3}$ films to be equal; the corresponding absorption spectra are shown in Figure S2 (Supporting Information).

Parts a $-\mathrm{c}$ of Figure 6 show normalized steady-state emission spectra of $\mathrm{TiO}_{2}$ films of YD0-YD2, respectively; parts d-f of Figure 6 show the normalized steady-state emission spectra of $\mathrm{Al}_{2} \mathrm{O}_{3}$ films of YD0-YD2, respectively. These results indicate three important features: (i) the thin-film spectra exhibit a broad red-shifted spectral feature relative to their solution spectra, indicating the significance of dye aggregation on the surface of semiconductors; (ii) the emission spectra of $\mathbf{Y D 1}$ on $\mathrm{Al}_{2} \mathrm{O}_{3}$ films are shifted toward the solution spectra upon addition of CDCA at various ratios, but the spectral shifts of YD2 are insensitive to the presence of CDCA on either film; and (iii) the relative intensities of the emissions of the $\mathrm{Al}_{2} \mathrm{O}_{3}$ films are significantly greater than those of the corresponding $\mathrm{TiO}_{2}$ films, indicating the occurrence of electron injection from the excited state of a porphyrin to the conduction band of $\mathrm{TiO}_{2}$. Thus time-resolved information is crucial for understanding the details of electron injection occurring at the dye/ $/ \mathrm{TiO}_{2}$ interface and the intermolecular energy transfer of the dye molecules on the surface of the films.

With excitation of thin-film samples at $430 \mathrm{~nm},{ }^{4 \mathrm{~h}, 6 \mathrm{~b}}$ the emissions at the maximum intensity were optically gated with the fundamental pulse $(860 \mathrm{~nm})$ to yield the emission decays of YD0-YD2 on $\mathrm{TiO}_{2}$ films as shown in Figure $7 \mathrm{a}-\mathrm{c}$, respectively, and on $\mathrm{Al}_{2} \mathrm{O}_{3}$ films as shown in Figure $7 \mathrm{~d}-\mathrm{f}$, respectively. These transients show decays much more rapid for YD1 and YD2 than for YD0 and for $\mathrm{TiO}_{2}$ films than for $\mathrm{Al}_{2} \mathrm{O}_{3}$ films, but slower when more CDCA is added; such a feature was not obvious for YD2. The temporal profiles of all thin-film samples are characterized with a multiexponential decay; the corresponding time coefficients were obtained on analyzing the data with a parallel kinetic model

$$
\begin{aligned}
& \mathrm{A} \stackrel{\tau_{1}}{\rightarrow} \mathrm{B} \\
& \mathrm{A}^{\prime} \stackrel{\tau_{2}}{\longrightarrow} \mathrm{B}^{\prime} \\
& \mathrm{A}^{\prime \prime} \stackrel{\tau_{3}}{\longrightarrow} \mathrm{B}^{\prime \prime}
\end{aligned}
$$

In this model, we assume that $\mathrm{A}, \mathrm{A}^{\prime}$, and $\mathrm{A}^{\prime \prime}$ are excited-state species of the dye molecule at separate sites of the surface of the semiconductor undergoing nonradiative relaxations through distinct channels to the corresponding dark states, $\mathrm{B}, \mathrm{B}^{\prime}$, and $\mathrm{B}^{\prime \prime} ; \tau_{1}, \tau_{2}$, and $\tau_{3}$ are their corresponding first-order decay coefficients. For $\mathrm{Al}_{2} \mathrm{O}_{3}$ films, three decay components are required to fit the fluorescence transients; for $\mathrm{TiO}_{2}$ films, only two components are sufficient for the fits. The detailed deconvoluted components of the fitted curves are shown in Figures S3-S5 (Supporting Information) for YD0-YD2, respectively.

The relaxations of porphyrins on $\mathrm{TiO}_{2}$ and $\mathrm{Al}_{2} \mathrm{O}_{3}$ films exhibit such a multiple-exponential feature because of the surface inhomogeneity of the semiconductors. To resolve the kinetics resulting from energy transfer and electron injection, we averaged the time coefficients according to the amplitudeaveraged decay periods, ${ }^{16}$ i.e., $\tau_{\mathrm{TiO}_{2}}=\tau_{1} A_{1}+\tau_{2} A_{2}$ and $\tau_{\mathrm{Al}_{2} \mathrm{O}_{3}}=$ $\tau_{1} A_{1}+\tau_{2} A_{2}+\tau_{3} A_{3} ; A_{i}$ represents the relative amplitudes, subject 


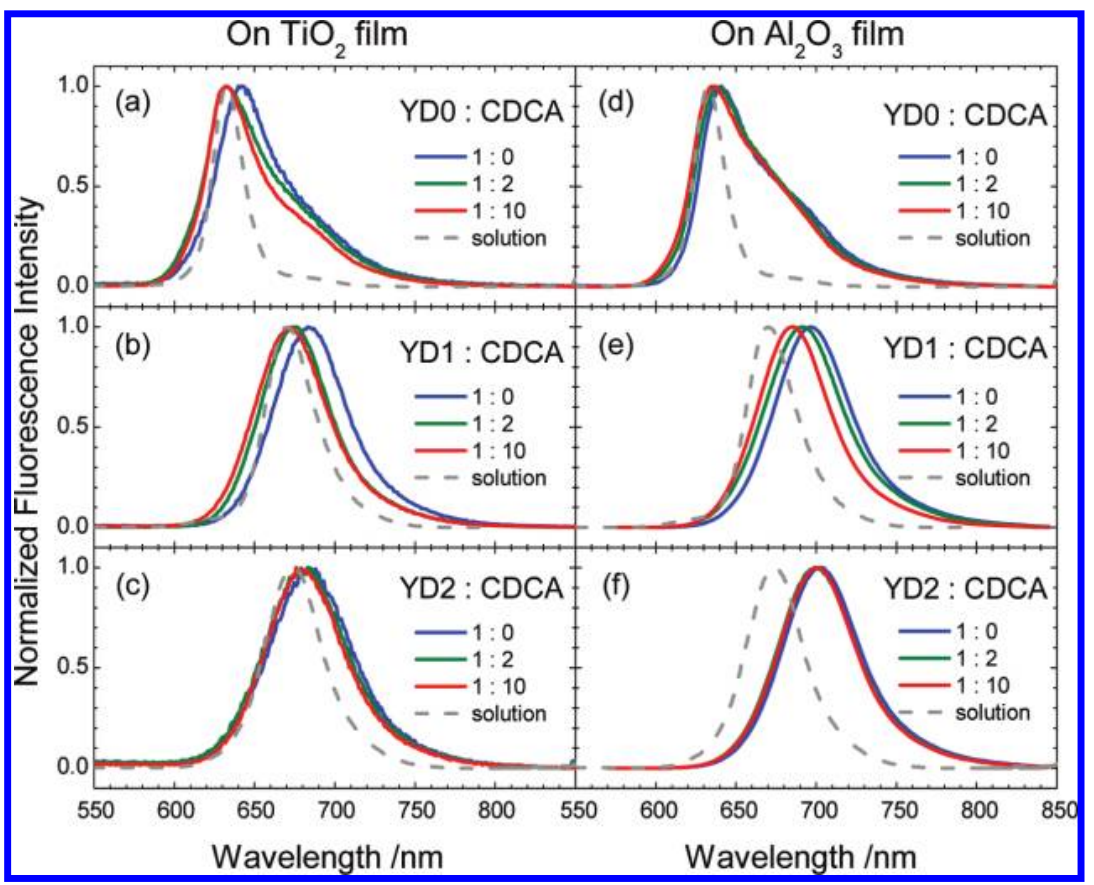

Figure 6. Steady-state fluorescence spectra of samples $(L \approx 5 \mu \mathrm{m})$ of the same type as used for measurements of femtosecond fluorescence up-conversion: YD0-YD2 with varying CDCA ratios coadsorbed on $(\mathrm{a}-\mathrm{c}) \mathrm{TiO}_{2}$ films and $(\mathrm{d}-\mathrm{f}) \mathrm{Al}_{2} \mathrm{O}_{3}$ films.

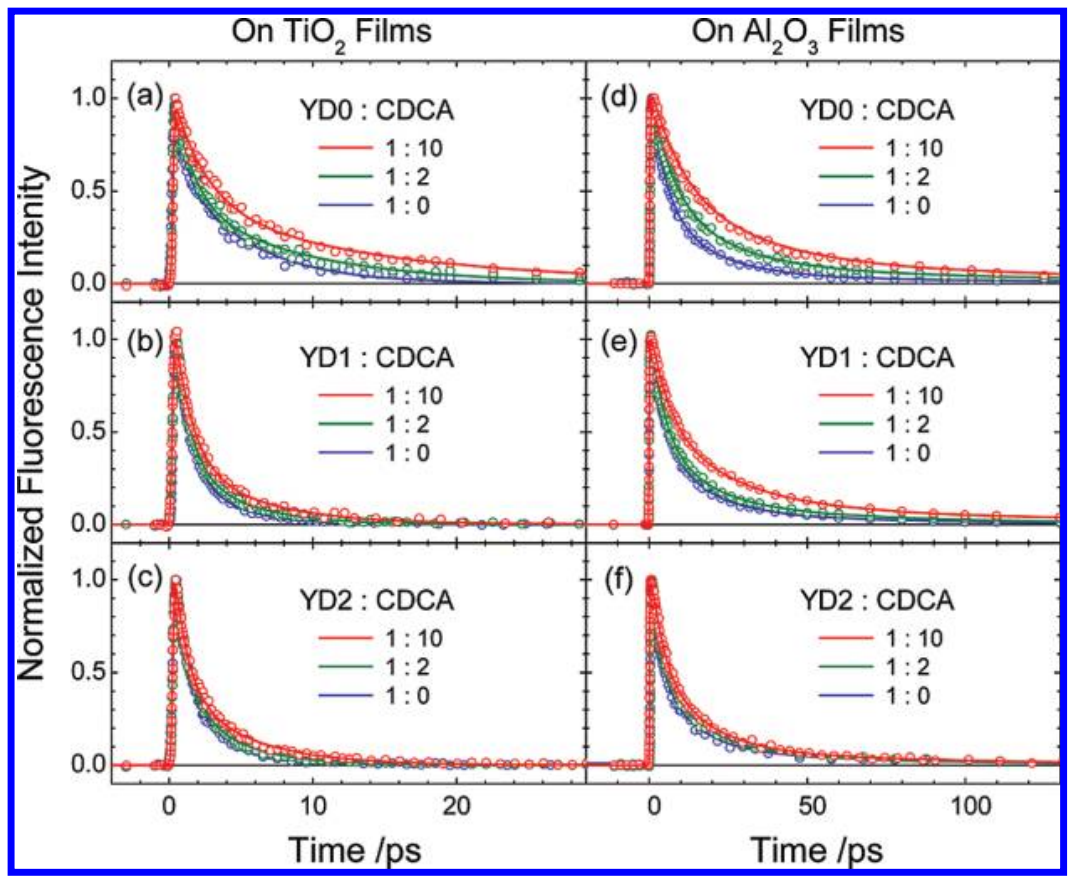

Figure 7. Femtosecond fluorescence decays of samples $(L \approx 5 \mu \mathrm{m})$ obtained from measurements of femtosecond fluorescence up-conversion: transients of YD0-YD2 with varying CDCA ratios coadsorbed on $(\mathrm{a}-\mathrm{c}) \mathrm{TiO}_{2}$ films and $(\mathrm{d}-\mathrm{f}) \mathrm{Al}_{2} \mathrm{O}_{3}$ films.

to the condition $\sum_{i} A_{i}=1.0$. The corresponding rate coefficients were determined according to $k_{\mathrm{TiO}_{2}}=\tau_{\mathrm{TiO}_{2}}{ }^{-1}$ and $k_{\mathrm{Al}_{2} \mathrm{O}_{3}}=\tau_{\mathrm{Al}_{2} \mathrm{O}_{3}}{ }^{-1}$. The emission decays of the porphyrin/ $/ \mathrm{Al}_{2} \mathrm{O}_{3}$ films reflect only the intermolecular energy transfer because of aggregation of the dye on the $\mathrm{Al}_{2} \mathrm{O}_{3}$ surface, but the emission decays of the porphyrin/ $/ \mathrm{TiO}_{2}$ films not only contain the aggregate-induced energy transfer but also reflect the rapid electron injection from the excited state of the dye into the conduction band of $\mathrm{TiO}_{2}$. If we assume that the extents of dye aggregation on the two films are similar, based on the same amounts of dye molecules adsorbed on the films with similar nanostructural morphologies, the rate coefficient for electron injection from an excited porphyrin into the $\mathrm{TiO}_{2}$ surface is determined by $k_{\mathrm{inj}} \approx k_{\mathrm{TiO}_{2}}$
- $k_{\mathrm{Al}_{2} \mathrm{O}_{3}}$. These amplitude-averaged kinetic parameters for YD0-YD2 with varying CDCA ratios sensitized on the $\mathrm{TiO}_{2}$ and $\mathrm{Al}_{2} \mathrm{O}_{3}$ films are summarized in Table 2 .

The rate coefficients $\left(k_{\mathrm{Al}_{2} \mathrm{O}_{3}}\right)$ for aggregate-induced energy transfer decrease in the order YD2 > YD1 > YD0 in the absence of CDCA, but the decrease of the rate coefficients in the presence of CDCA is in the oppositely order; e.g., for a dye/ CDCA ratio varying from 1:0 to $1: 10$, the values of $k_{\mathrm{Al}_{2} \mathrm{O}_{3}}$ for YD0 decreased by two-thirds, but those of YD2 decreased by only $\sim 20 \%$. The large $k_{\mathrm{Al}_{2} \mathrm{O}_{3}}$ values and great spectral shifts of films vs solution (Figure 6f) of YD2 indicate the occurrence of dye aggregation to some extent on semiconductor films, but the small variation of $k_{\mathrm{Al}_{2} \mathrm{O}_{3}}$ and the small spectral shifts with 
TABLE 2: Kinetic Parameters of $\mathrm{TiO}_{2}$ and $\mathrm{Al}_{2} \mathrm{O}_{3}$ Films $(L \approx 5 \mu \mathrm{m})$ Sensitized with YD0-YD2 Coadsorbed with Varying CDCA Ratios Obtained from Analysis of Femtosecond Fluorescence Decays Shown in Figure $7^{a}$

\begin{tabular}{|c|c|c|c|c|c|c|c|}
\hline dye & dye/CDCA ratio & $\tau_{\mathrm{TiO}_{2}}(\mathrm{ps})$ & $\tau_{\mathrm{Al}_{2} \mathrm{O}_{3}}(\mathrm{ps})$ & $k_{\mathrm{TiO}_{2}}\left(10^{11} \mathrm{~s}^{-1}\right)$ & $k_{\mathrm{Al}_{2} \mathrm{O}_{3}}\left(10^{11} \mathrm{~s}^{-1}\right)$ & $k_{\text {inj }}\left(10^{11} \mathrm{~s}^{-1}\right)$ & $\Phi_{\text {inj }}(\%)$ \\
\hline \multirow[t]{3}{*}{ YD0 } & 1:0 & $2.55 \pm 0.15$ & $13.5 \pm 2.7$ & $3.92 \pm 0.23$ & $0.74 \pm 0.14$ & $3.18 \pm 0.27$ & $0.81 \pm 0.08$ \\
\hline & $1: 2$ & $4.52 \pm 0.22$ & $23.5 \pm 4.7$ & $2.21 \pm 0.11$ & $0.43 \pm 0.09$ & $1.78 \pm 0.14$ & $0.81 \pm 0.08$ \\
\hline & $1: 10$ & $6.67 \pm 0.35$ & $41.4 \pm 5.5$ & $1.50 \pm 0.08$ & $0.24 \pm 0.03$ & $1.26 \pm 0.09$ & $0.84 \pm 0.07$ \\
\hline \multirow{2}{*}{ YD1 } & $1: 2$ & $1.96 \pm 0.09$ & $14.8 \pm 2.8$ & $5.10 \pm 0.23$ & $0.68 \pm 0.12$ & $4.42 \pm 0.26$ & $0.87 \pm 0.06$ \\
\hline & $1: 10$ & $2.57 \pm 0.12$ & $23.4 \pm 3.2$ & $3.89 \pm 0.18$ & $0.43 \pm 0.06$ & $3.46 \pm 0.19$ & $0.89 \pm 0.06$ \\
\hline YD2 & $1: 0$ & $1.71 \pm 0.10$ & $10.5 \pm 1.6$ & $5.85 \pm 0.34$ & $0.95 \pm 0.14$ & $4.90 \pm 0.37$ & $0.84 \pm 0.08$ \\
\hline
\end{tabular}

${ }^{a}$ Average time coefficients obtained from raw data shown in Figures S3-S5 (Supporting Information), using the amplitude-averaged decay times. The uncertainties represent two standard deviations obtained from nonlinear curve fitting and subsequent data analysis.

increasing amount of CDCA imply that the coadsorbate cannot effectively suppress porphyrin aggregation for YD2. The porphyrins hence seemed to form aggregate clusters on semiconductor films. When CDCA is added for YD0 and YD1, the coadsorbate might enter the interspace of each cluster so that $k_{\mathrm{Al}_{2} \mathrm{O}_{3}}$ decreases substantially; for YD2, CDCA might enter the interspace of the aggregate clusters less effectively, probably because of the hindrance of the two hydrophobic hexyl chains, so that $k_{\mathrm{Al}_{2} \mathrm{O}_{3}}$ decreases only slightly.

The rate coefficients $\left(k_{\text {inj }}\right)$ for electron injection of YD1 and YD2 are significantly larger than that of YD0, reflecting the superior electron-donating ability of the former with the diarylamino substituents. The values of $k_{\text {inj }}$ also depend on the dye/ CDCA ratio for all three porphyrins: the more CDCA added, the smaller the value of $k_{\text {inj. }}$ For an increas in the dye/CDCA ratio from 1:0 to $1: 10, k_{\text {inj }}$ decreased in the order YD0 $>$ YD1 $\approx$ YD2. Porphyrin aggregation on $\mathrm{TiO}_{2}$ surfaces thus not only accelerates the rate of intermolecular energy transfer, represented by $k_{\mathrm{Al}_{2} \mathrm{O}_{3}}$, but also increases, to some extent, the rate of interfacial electron injection represented by $k_{\text {inj, }}$, so that the yields of electron injection are balanced by these two important factors.

Electron injection from an electronically excited state of a porphyrin into the conduction band of $\mathrm{TiO}_{2}$ competes with other radiative or nonradiative relaxation channels. The quantum yield, $\Phi_{\text {inj }}$, for electron injection, which defines the fraction of photons absorbed by the porphyrin that become converted into electrons in the conduction band of $\mathrm{TiO}_{2}$, is formulated as

$$
\begin{aligned}
\Phi_{\mathrm{inj}}=\frac{k_{\mathrm{inj}}}{k_{\mathrm{inj}}+k_{\mathrm{agg}}+k_{\mathrm{nr}}+k_{\mathrm{r}}}=\frac{k_{\mathrm{inj}}}{k_{\mathrm{TiO}_{2}}} \approx \\
\left(\tau_{\mathrm{TiO}_{2}}^{-1}-\tau_{\mathrm{Al}_{2} \mathrm{O}_{3}}{ }^{-1}\right) \tau_{\mathrm{TiO}_{2}}=1-\frac{\tau_{\mathrm{TiO}_{2}}}{\tau_{\mathrm{Al}_{2} \mathrm{O}_{3}}}
\end{aligned}
$$

where $k_{\text {agg }}$ represents the nonradiative rate coefficient for aggregate-induced energy transfer so that it is equal to $k_{\mathrm{Al}_{2} \mathrm{O}_{3}}$. $k_{\mathrm{r}}$ and $k_{\mathrm{nr}}$ represent the rate coefficients for radiative and other nonradiative (e.g., intersystem crossing) processes, respectively. The values of $\Phi_{\text {inj }}$ calculated according to eq 3 are summarized in the rightmost column of Table 2. For both YD0 and YD1, $\Phi_{\text {inj }}$ increased slightly with increasing amount of CDCA because the rate of energy transfer decreased more than the rate of electron injection, but $\Phi_{\text {inj }}$ decreased slightly with increasing amount of CDCA for YD2 because the variation of the rate coefficients was in the other direction. Even though the variations are within the experimental uncertainties, our results are consistent with the presence of CDCA not improving the photovoltaic performance for YD2 as it did for YD0 and YD1.
Because of similar APCE values for YD1 (1:2) and YD2 (1:0), $\Phi_{\text {inj }}$ for YD1 being larger than that for YD2 implies that the efficiency of charge collection of YD2 is superior to that of YD1 through an advantage of two long hydrophobic alkyl chains in the diarylamino group of YD2.

2.5. Optimization of Cell Performance for YD0-YD2 on Thicker $\mathrm{TiO}_{2}$ Films. At the optimal conditions for the YD0-YD2 devices, we performed photovoltaic measurements for the three porphyrins sensitized on $\mathrm{TiO}_{2}$ films with thicknesses of $\sim 10 \mu \mathrm{m}$ without and with an added scattering layer with a thickness of $\sim 4 \mu \mathrm{m}$. We similarly performed photovoltaic measurements of YD0-YD2 and N719 with three identical working electrodes under the same experimental conditions. The raw data for each current-voltage $(J-V)$ measurement are summarized in Tables S5 and S6 (Supporting Information) for $\mathrm{TiO}_{2}$ films without and with the scattering layer, respectively; the corresponding average photovoltaic parameters are summarized in Table 3 . Figure 8a,b shows typical $J-V$ curves (working electrode a in Tables S5 and S6, Supporting Information) for $\mathrm{TiO}_{2}$ films without and with the scattering layer, respectively; the corresponding IPCE spectra appear in Figure $8 \mathrm{c}, \mathrm{d}$. Integrating the IPCE over the AM 1.5G solar spectra again yielded calculated $J_{\mathrm{SC}}$ values that matched perfectly with the collected values for all devices under investigation (see Figure S6 in the Supporting Information).

Our results indicate that both YD1 (1:2) and YD2 (1:0) exhibit remarkable performances relative to $\mathbf{N 7 1 9}$ (1:1) without a scattering layer; the performance of YD0 (1:2) is significantly less than that of the others. YD2 performs even better than YD1 because the larger $J_{\mathrm{SC}}$ value results from the more intense and broader IPCE spectrum shown in Figure 8c. The $J_{\mathrm{SC}}$ values of these two promising porphyrin-based devices, YD1 and YD2, are greater than that of the $\mathbf{N 7 1 9}$ device. Even though the $V_{\mathrm{OC}}$ and FF values for the former are smaller than those for the latter, the net effects of these variations make the overall efficiencies of power conversion of the YD1 and YD2 devices superior to that of the N719 device. YD1 $(\eta=6.4 \%)$ and YD2 $(\eta=6.6 \%)$ are thus two green sensitizers that are remarkable for their outstanding cell performances relative to that of $\mathbf{N 7 1 9}(\eta=$ $6.3 \%$ ) without an added scattering layer for green-lightpenetrable DSSC applications.

When $\mathrm{TiO}_{2}$ films with thicknesses of $\sim 10 \mu \mathrm{m}$ were covered with a scattering layer with a thickness of $\sim 4 \mu \mathrm{m}$, the cell performance of $\mathbf{N 7 1 9}$ was improved significantly to $\eta=7.3 \%$, whereas the performances of the porphyrin dyes increased only slightly, to $\eta=6.5 \%$ and $6.8 \%$ for YD1 and YD2, respectively. The IPCE spectra of YD1 and YD2 exhibit a large gap between the Soret and the Q bands without a scattering layer (Figure 8c), but this gap is decreased for the $\mathrm{TiO}_{2}$ films with a scattering 
TABLE 3: Photovoltaic Parameters of DSSCs with $\mathrm{TiO}_{2}$ Films $[L \approx 10$ or $(10+4) \mu \mathrm{m}]$ Sensitized with YD0-YD2 and N719 Coadsorbed with Varying CDCA Ratios under Simulated AM-1.5 Illumination (Power $=100 \mathrm{~mW} \mathrm{~cm}^{-2}$ ) and an Active Area of $0.16 \mathrm{~cm}^{2} a$

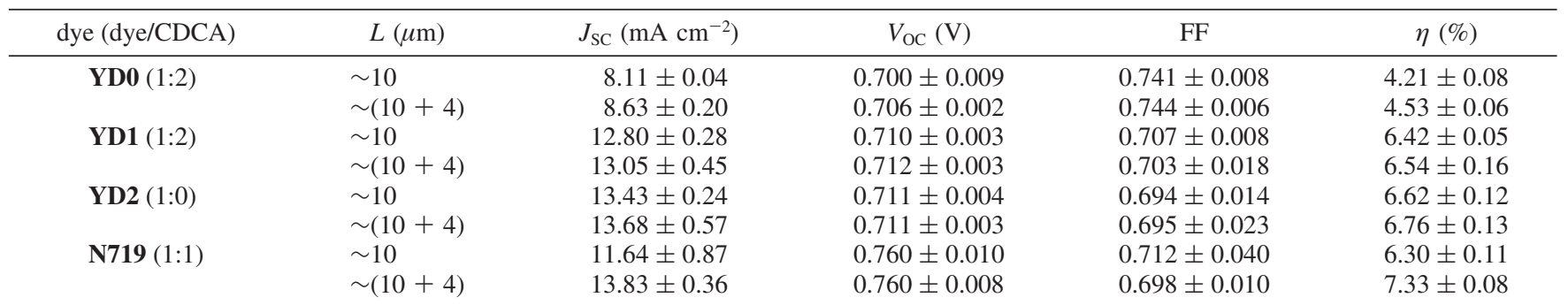

${ }^{a}$ The photovoltaic parameters are averaged values obtained from analysis of the $J-V$ curves of three identical working electrodes for each device fabricated and characterized under the same experimental conditions; the raw data of each $J-V$ measurement are summarized in Tables S5 and S6 (Supporting Information), for $L / \mu \mathrm{m} \approx 10$ and $\approx(10+4)$, respectively; the uncertainties represent two standard deviations of the measurements.

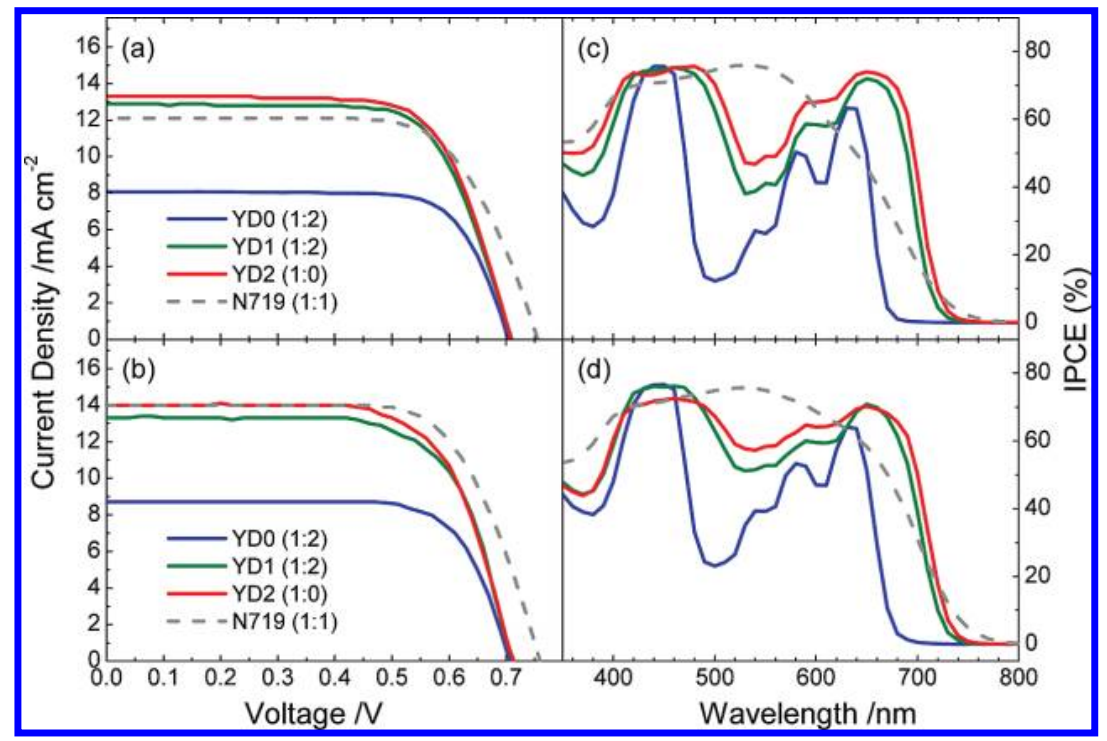

Figure 8. Optimal current-voltage characteristics of DSSC devices YD0-YD2 (working electrode a in the Supporting Information) on TiO films $_{2}$ (thickness $\approx 10 \mu \mathrm{m}$ ) (a) without a scattering layer and (b) with a scattering layer (thickness $\approx 4 \mu \mathrm{m}$ ) under illumination of simulated AM1.5G full sunlight $\left(100 \mathrm{~mW} \mathrm{~cm}^{-2}\right)$ and an active area $0.16 \mathrm{~cm}^{2}$. (c,d) Corresponding IPCE action spectra. The gray dashed curves in all plots show the results for N719 devices for comparison.

layer (Figure 8d). The shoulders of the efficiency spectra on the red side extended no further beyond the edge of the $\mathrm{Q}$ band in the presence of a scattering layer; for this reason, only a slight improvement in $J_{\mathrm{SC}}$ was found for the porphyrin-based DSSCs with a scattering layer. In contrast, the cell performance improved significantly for an N719-based DSSC with a scattering layer because of the effective scattering effect in the red shoulder of the efficiency spectrum.

\section{Summary and Concluding Remarks}

We report here photovoltaic performances and femtosecond fluorescence kinetics for three porphyrin sensitizers (YD0-YD2) coadsorbed with chenodeoxycholic acid (CDCA) at three molar ratios on nanocrystalline semiconductor films of $\mathrm{TiO}_{2}$ and $\mathrm{Al}_{2} \mathrm{O}_{3}$. Our photovoltaic results revealed three important points summarized as follows: First, devices YD1 and YD2 made of porphyrins with electron-donating substituents outperform reference cell YD0 because of the effective electronic coupling between the diarylamino group and the porphyrin core that makes the IPCE spectra of the former much broader and red-shifted compared to the latter. Second, the addition of CDCA improved the cell performances of YD0 and YD1 to attain the greatest efficiencies at a dye/CDCA ratio of 1:2, but the presence of CDCA had a negative effect for YD2. Third, the efficiencies of power conversion of YD1 and YD2 are slightly greater than that of $\mathbf{N 7 1 9}(6.4 \%$ and $6.6 \%$ vs $6.3 \%)$ without an added scattering layer on $\mathrm{TiO}_{2}$ film with a thickness of $\sim 10 \mu \mathrm{m}$, but when the $10-\mu \mathrm{m} \mathrm{TiO}_{2}$ films were covered with a scattering layer with a thickness of $\sim 4 \mu \mathrm{m}$, the cell performance of $\mathbf{N 7 1 9}$ significantly improved to $\eta=7.3 \%$, whereas the performances of YD1 and YD2 increased only slightly, to $\eta=6.5 \%$ and $6.8 \%$. The reason is that the shoulders of the IPCE spectra of YD1 and YD2 on the red side extended no further beyond the edge of the $\mathrm{Q}$ band, but such a scattering effect in the red shoulder significantly enhanced $J_{\mathrm{SC}}$ for device N719 with a scattering layer.

The superlative cell performances of YD1 and YD2 are due to their large $J_{\mathrm{SC}}$ values, which arise from the uniformly large efficiency broadly covering the entire visible region of the solar spectrum. The diarylamino group attached at the meso position of the porphyrin core not only extends the absorption spectrally to a region of greater wavelength but also pushes the excited electrons spatially toward the $\mathrm{TiO}_{2}$ film for an improved charge separation. Both YD1 and YD2 adsorbed on a $\mathrm{TiO}_{2}$ surface exhibit a long-lived cationic spectral feature corresponding to the absorption bands at $\sim 800$ and $\sim 1350 \mathrm{~nm}$ for their protracted charge recombination, whereas this spectral feature was absent when they were adsorbed on $\mathrm{Al}_{2} \mathrm{O}_{3}$ films or for YD0 adsorbed 
on both films. The existence of the enduring charge-separation state in the porphyrin-sensitized $\mathrm{TiO}_{2}$ films implies that the interception of conduction-band electrons is controlled solely by recombination of the electrons with $\mathrm{I}_{3}{ }^{-}$in the electrolyte. That the cell performances of YD1 and YD2 are superior to that of YD0 is thus due to the diminished recombination between $\mathrm{I}_{3}{ }^{-}$and conduction-band electrons, because $\mathrm{I}_{3}{ }^{-}$might attach to the positively charged diarylamino moiety far from the $\mathrm{TiO}_{2}$ surface.

Because dye aggregation is an important issue for further improvement of the cell performance for porphyrin-based DSSC, we investigated the excited-state relaxation dynamics of YD0-YD2 with $\mathbf{N 7 1 9}$ at various ratios coadsorbed on $\mathrm{TiO}_{2}$ or $\mathrm{Al}_{2} \mathrm{O}_{3}$ films (thickness $\approx 5 \mu \mathrm{m}$ ) using femtosecond fluorescence up-conversion. The order of rates of aggregate-induced energy transfer of porphyrins on $\mathrm{Al}_{2} \mathrm{O}_{3}$ films is YD2 > YD1 > YD0 in the absence of CDCA, but the rate of energy transfer in the presence of CDCA decreased much less for YD2 than for YD0 and YD1. The rates of electron injection of YD1 and YD2 are significantly greater than those of YD0, confirming that the involvement of the diarylamino substitutes in YD1 and YD2 has a dynamic effect to push the electrons efficiently toward $\mathrm{TiO}_{2}$. As the rates of electron injection for all three porphyrins decreased when more CDCA was added, porphyrin aggregation on $\mathrm{TiO}_{2}$ surfaces not only accelerated the rate of intermolecular energy transfer but also increased the rate of interfacial electron injection so that the yields $\left(\Phi_{\text {inj }}\right)$ of electron injection were balanced by these two important factors. As a result, $\Phi_{\text {inj }}$ increased slightly with increasing amount of CDCA for both YD0 and YD1, but the variation in $\Phi_{\text {inj }}$ was reversed for YD2 because the rate of electron injection decreased more significantly than the rate of energy transfer for the latter. The femtosecond results thus explain why the presence of CDCA failed to improve the photovoltaic performance for YD2 unlike for YD0 and YD1. The presence of CDCA suppresses dye aggregation, decreases the amount of dye loading on the $\mathrm{TiO}_{2}$ surface and diminishes electron injection from dye to $\mathrm{TiO}_{2}$; the overall performance of a porphyrin-based DSSC is thus a subtle balance between these factors.

Acknowledgment. The National Science Council of Taiwan and Ministry of Education of Taiwan, under the ATU program, provided support for this project.

Supporting Information Available: Synthesis and characterization of YD2, electrode preparation and device fabrication, effect of dye loading, photovoltaic characterization, femtosecond fluorescence spectra, and supplementary tables (Tables S1-S6) and figures (Figures S1-S6). This material is available free of charge via the Internet at http://pubs.acs.org.

\section{References and Notes}

(1) (a) O'Regan, B.; Grätzel, M. Nature 1991, 353, 737. (b) Nazeeruddin, M. K.; Kay, A.; Rodicio, I.; Humphry-Baker, R.; Müller, E.; Liska,
P.; Vlachopoulos, N.; Grätzel, M. J. Am. Chem. Soc. 1993, 115, 6382. (c) Grätzel, M. Inorg. Chem. 2005, 44, 6841.

(2) (a) Wang, Q.; Ito, S.; Grätzel, M.; Fabregat-Santiago, F.; MoraSeró, I.; Bisquert, J.; Bessho, T.; Imai, H. J. Phvs. Chem. B 2006, 110, 25210. (b) Gao, F.; Wang, Y.; Shi, D.; Zhang, J.; Wang, M.; Jing, X.; Humphry-Baker, R.; Wang, P.; Zakeeruddin, S. M.; Grätzel, M. $\underline{\text { J. Am. }}$ Chem. Soc. 2008, 130, 10720.

(3) (a) Robertson, N. Angew. Chem. Int. Ed. 2006, 45, 2338. (b) Hamann, T. W.; Jensen, R. A.; Martinson, A. B. F.; Ryswyk, H. V.; Hupp, J. T. Energy Environ. Sci. 2008, 1, 66. (c) Mishra, A.; Fischer, M. K. R.; Bäuerle, P. Angew. Chem., Int. Ed. 2009, 48, 2474. (d) Imahori, H.; Umeyama, T.; Ito, S. Acc. Chem. Res., published online May 1, 2009, http:// dx.doi.org/10.1021/ar900034t.

(4) (a) Wang, Q.; Campbell, W. M.; Bonfantani, E. E.; Jolley, K. W.; Officer, D. L.; Walsh, P. J.; Gordon, K.; Humphry-Baker, R.; Nazeeruddin, M. K.; Grätzel, M. J. Phvs. Chem. B 2005, 109, 15397. (b) Campbell, W. M.; Jolley, K. W.; Wagner, P.; Wagner, K.; Walsh, P. J.; Gordon, K. C.; Schmidt-Mende, L.; Nazeeruddin, M. K.; Wang, Q.; Grätzel, M.; Officer, D. L. J. Phvs. Chem. C 2007, 111, 11760. (c) Rochford, J.; Chu, D.; Hagfeldt, A.; Galoppini, E. J. Am. Chem. Soc. 2007, 129, 4655. (d) Eu, S.; Hayashi, S.; Umeyama, T.; Oguro, A.; Kawasaki, M.; Kadota, N.; Matano, Y.; Imahori, H. J. Phvs. Chem. C 2007, 111, 3528. (e) Stromberg, J. R.; Marton, A.; Kee, H. L.; Kirmaier, C.; Diers, J. R.; Muthiah, C.; Taniguchi, M.; Lindsey, J. S.; Bocian, D. F.; Meyer, G. J.; Holten, D. J. Phvs. Chem. C 2007, 111, 15464. (f) Hayashi, S.; Tanaka, M.; Hayashi, H.; Eu, S.; Ümeyama, T.; Matano, Y.; Araki, Y.; Imahori, H. J. Phvs. Chem. C 2008, 112, 15576. (g) Park, J. K.; Lee, H. R.; Chen, J.; Shinokubo, H.; Osuka, A.; Kim, D. J. Phys. Chem. C 2008, 112, 16691. (h) Lin, C.-Y.; Lo, C.-F.; Luo, L.; Lu, H.-P.; Hung, C.-S.; Diau, E. W.-G. J. Phvs. Chem. C 2009, 113, 755. (i) de Tacconi, N. R.; Chanmanee, W.; Rajeshwar, K.; Rochford, J.; Galoppini, E. J. Phys. Chem. C 2009, 113, 2996.

(5) Lee, C.-W.; Lu, H.-P.; Lan, C.-M.; Huang, Y.-L.; Liang, Y.-R.; Yen, W.-N.; Liu, Y.-C.; Lin, Y.-S.; Diau, E. W.-G.; Yeh, C.-Y. Chem.-Eur. J. 2009, 115, 1403 .

(6) (a) Galoppini, E. Coord. Chem. Rev. 2004, 248, 1283. (b) Luo, L.-Y.; Lo, C.-F.; Lin, C.-Y.; Chang, I.-J.; Diau, E. W.-G. J. Phvs. Chem. B 2006, 110, 410. (c) Lo, C.-F.; Luo, L.; Diau, E. W.-G.; Chang, I.-J.; Lin, C.-Y. Chem. Commun. 2006, 1430.

(7) Wang, P.; Zakeeruddin, S. M.; Comte, P.; Charvet, R.; HumphryBaker, R.; Grätzel, M. J. Phys. Chem. B 2003, 107, 14336.

(8) Wang, M.; Li, X.; Lin, H.; Pechy, P.; Zakeeruddin, S. M.; Grätzel, M. Dalton Trans., published online 2009, http://dx.doi.org/10.1039/ b908673k.

(9) Lu, H.-P.; Mai, C.-L.; Tsia, C.-Y.; Hsu, S.-J.; Hsieh, C.-P.; Chiu, C.-L.; Yeh, C.-Y.; Diau, E. W.-G. Phvs. Chem. Chem. Phvs. 2009, 11, 10270 .

(10) (a) Hagberg, D. P.; Marinado, T.; Karlsson, K. M.; Nonomura, K.; Qin, P.; Boschloo, G.; Brinck, T.; Hagfeldt, A.; Sun, L. J. Org. Chem. 2007, 72, 9550. (b) Hagberg, D. P.; Yum, J.-H.; Lee, H.; De Angelis, F.; Marinado, T.; Karlsson, K. M.; Humphry-Baker, R.; Sun, L.; Hagfeldt, A.; Grätzel, M.; Nazeeruddin, Md. K. J. Am. Chem. Soc. 2008, 130, 6259. (c) Ooyama, Y.; Harima, Y. Eur. J. Org. Chem. 2009, 18, 2903.

(11) (a) Zakeeruddin, S. M.; Nazeeruddin, Md. K.; Humphry-Baker, R.; Péchy, P.; Quagliotto, P.; Barolo, C.; Viscardi, G.; Grätzel, M. Langmuir 2002, 18, 952. (b) Wang, P.; Zakeeruddin, S. M.; Moser, J. E.; Nazeeruddin, Md. K.; Sekiguchi, T.; Grätzel, M. Nat. Mater. 2003, 2, 402.

(12) (a) Hirata, N.; Lagref, J.-J.; Palomares, E. J.; Durrant, J. R.; Nazeeruddin, M. K.; Grätzel, M. Chem.-Eur. J. 2004, 10, 595. (b) Haque, S. A.; Handa, S.; Peter, K.; Palomares, E.; Thelakkat, M.; Durrant, J. R. Angew. Chem., Int. Ed. 2005, 44, 5740.

(13) Clifford, J. N.; Yahioglu, G.; Milgrom, L. R.; Durrant, J. R. Chem. Сотmun. 2002, 1260.

(14) Mozer, A. J.; Wagner, P.; Officer, D. L.; Wallace, G. G.; Campbell, W. M.; Miyashita, M.; Sunahara, K.; Mori, S. Chem. Commun. 2008, 4741.

(15) Halmes, J.; Boschloo, G.; Hagfeldt, A.; Lund, P. J. Phvs. Chem. C 2008, 112,5623

(16) Valeur, B. Molecular Fluorescence: Principles and Applications; Wiley-VCH: New York, 2002.

JP908100V 